\title{
World Journal of Emergency

\section{Ultrasound assessment of haemoperitoneum in ectopic pregnancy: derivation of a prediction model}

\author{
Arnaud Fauconnier*, Ali Mabrouk, Laurent J Salomon, Jean-Pierre Bernard \\ and Yves Ville
}

Address: Department of Gynaecology, Obstetrics and Reproductive medicine, CHI Poissy-St-Germain, Saint-Germain-En-Laye, France

Email: Arnaud Fauconnier* - afauconnier@chi-poissy-st-germain.fr; Ali Mabrouk - alimabrouk@hotmail.com;

Laurent J Salomon - laurentsalomon@wanadoo.fr; Jean-Pierre Bernard - ean-pierre.bernard12@wanadoo.fr; Yves Ville - yville@wanadoo.fr

* Corresponding author

Published: 7 September 2007

World Journal of Emergency Surgery 2007, 2:23 doi:10.1 186/1749-7922-2-23

This article is available from: http://www.wjes.org/content/2/I/23

(C) 2007 Fauconnier et al; licensee BioMed Central Ltd.

This is an Open Access article distributed under the terms of the Creative Commons Attribution License (http://creativecommons.org/licenses/by/2.0), which permits unrestricted use, distribution, and reproduction in any medium, provided the original work is properly cited.
Received: 19 February 2007

Accepted: 7 September 2007

\begin{abstract}
Background: To derive an ultrasound-based prediction model for the quantification of haemoperitoneum in ectopic pregnancy (EP).

Methods: Retrospective study of 89 patients operated upon EP between January 1999 and March 2003 in a French Gynaecology and Obstetrics department in a university hospital. Transvaginal sonograms, clinical and biological variables from patients with haemoperitoneum $\geq 300 \mathrm{ml}$ at surgery were compared with those from patients with haemoperitoneum $<300 \mathrm{ml}$ or no haemoperitoneum. Sensitivity, specificity, positive and negative likelihood ratios were calculated for each parameter after appropriate dichotomization. Multiple logistic regression analysis was used to select the best combination at predicting haemoperitoneum $\geq 300 \mathrm{ml}$.
\end{abstract}

Results: Three parameters predicted haemoperitoneum $\geq 300 \mathrm{ml}$ independently: moderate to severe spontaneous pelvic pain, fluid above the uterine fundus or around the ovary at transvaginal ultrasound, and serum haemoglobin concentration $<10 \mathrm{~g} / \mathrm{dL}$. A woman with none of these three criteria would have a probability of $5.3 \%$ for haemoperitoneum $\geq 300 \mathrm{ml}$. When two or more criterias were present, the probability for haemoperitoneum $\geq 300 \mathrm{ml}$ reached $92.6 \%$.

Conclusion: The proposed model accurately predicted significant haemoperitoneum in patients diagnosed to have EP.

\section{Background}

The combination of transvaginal ultrasound (US) and serum human chorionic gonadotropin (hCG) determination has proven to be reliable for the early diagnosis of ectopic pregnancy (EP) [1-4]. The goal of early diagnosis is the prevention of tubal rupture [5], which is the cause of most EP-related deaths [6,7], and is a surgical emergency. Accordingly, suspicion of tubal rupture is an abso- lute contraindication for medical treatment of EP using methotrexate [8-12].

Although, the diagnosis of tubal rupture is obvious when patients are haemodynamically unstable, symptoms in most cases of tubal rupture are more subtle [13-16]. The only diagnostic method to rule out tubal rupture would be to perform a laparoscopy in all cases [15]. 
However, considering that most tubal rupture would cause significant haemoperitoneum and that the latter would often correspond to tubal rupture is clinically sound. Evidence for haemoperitoneum is usually found on US examination. Nevertheless, the various US criteria used to quantify the amount of the haemoperitoneum prior to surgery $[12,17-21]$ have not been validated yet.

The aim of our study was therefore to identify criterias in the pre operative work-up that could be useful to predict the haemoperitoneum volume, in a homogeneous series of patients operated upon EP.

\section{Methods \\ Study population}

All patients assigned for surgical treatment for EP between January 1999 and March 2003, by laparoscopy or by laparotomy, were included in the study.

The patients were identified from the hospital's computerized Medical Information System. The indication for surgical treatment of EP was left to the attending consultant gynaecologist, and surgery took place either at the time of presentation or after failure of medical treatment using methotrexate. At our institution medical treatment is offered on the basis of: absence of significant pain and stable hemodynamics, normal serum haemoglobin concentration and white cell count as well as serum hCG concentration < $5000 \mathrm{IU} / \mathrm{L}$; patient accepting the medical treatment and its follow-up.

\section{Variables of interest}

The following parameters were collected from the medical records: age, gravidity, parity, gestational age, the existence of vaginal bleeding, the existence and severity of spontaneous pelvic pain, systolic and diastolic blood pressure, pulse rate, pre operative serum haemoglobin concentration $(\mathrm{g} / \mathrm{dL})$ and pre operative serum hCG concentration $(\mathrm{UI} / \mathrm{L})$. All these parameters were collected at presentation. The severity of spontaneous pelvic pain was subjectively assessed by the specialist registrar, in a semiquantitative fashion using four levels: absent, mild, moderate, or severe [22].

Transvaginal US investigation was carried out pre operatively in all cases by the registrar or the consultant. One of three US machines were used: a Voluson ${ }^{\circledast} 530 \mathrm{D}$ MT, fitted with a $7.5 \mathrm{MHZ}$ convex transvaginal probe S-EW5/7K (Kretztechnik AG), a Logic 700, fitted with a $5.6 \mathrm{MHZ}$ convex transvaginal probe 618E (GE Medical System), and a Logic 500 fitted with a 4.8 MHZ convex transvaginal probe E721 (GE Medical System). It is the policy in our institution to record images of a standardised sonogram in cases with EP. At least, three pictures are requested: one of the uterus in a stricly midsagittal plane from the uterine cervix to the fundus; one of each ovary in there greater diameter. In case of abnormal extra-uterine finding one or more picture were requested. All sonograms were carefully reviewed for the study, in order to ensure a standardised analysis of the characteristics of intraperitoneal effusion. All ultrasound records were reviewed by one trained specialist registrar (AM) under the direct supervision of a senior operator skilled in the practice of gynaecological ultrasound (J-PB). This review was carried out blindly to the quantification of haemoperitoneum as stated in the surgery report. The presence of free fluid in the Pouch of Douglas was defined by the presence of liquid behind the uterus on a strictly midsagittal plane. The volume of the intraperitoneal fluid was assessed in semi-quantitative way according to the level reached relative to the uterus on a midsagittal plane: (i) below or at the level of the uterine isthmus; (ii) reaching the uterine body; (iii) exceeding the uterine fundus. This classification was adapted from another study [18]. Fluid around the ovary or in the vesico-uterine pouch was also noted. The fluid was described as echogenous if fine, diffuse echos were visible in the liquid $[23,24]$, and the presence of clots was noted if there were heterogeneous areas within the fluid [25].

A quantitative estimate of the haemoperitoneum in $\mathrm{ml}$, was carried out during surgery by recording of the volume aspirated and irrigation fluid. Presence or absence of tubal rupture was also noted.

\section{Statistical analysis}

The study population was split into two groups according to the volume of the haemoperitoneum found at surgery: one group of patients with a haemoperitoneum volume quantified equal to or above the median volume; one group of patients with no haemoperitoneum or below the median volume.

The two groups were compared using Pearson's ChiSquare test for qualitative variables and Student's $t$ test for quantitative variables. The continuous and ordinal variables found to be associated with haemoperitoneum equal to or above the median volume at a threshold of $\mathrm{p}<0.10$ in the univariate analysis were then dichotomised to enable their use in a prediction model. The diagnostic value of each variable was estimated by calculating the sensitivity (Se), specificity (Sp), positive likelihood ratio (LR) and negative LR. When a variable presented several possible cut-off levels, the one chosen was either that which gave maximum Se or maximum Sp [26].

Multiple logistic regression analysis was then used in order to select the best combination of variables to predict the presence of a haemoperitoneum equal to or above the median volume. The condition for variables to be included in the logistic regression model was the fact of 
presenting a sufficiently high diagnostic value: negative LR $\leq 0.25$ for variables with high sensitivity [26]; or positive LR $\geq 4$ for variables with high specificity [26]. A backward stepwise procedure was then used to remove variables so that the final model included only those variables independently associated with haemoperitoneum equal to or above the median volume at a threshold of $\mathrm{p}$ $<0.05$.

The variables thus selected were then combined with each other and the diagnostic performance of each of the various combinations for prediction of haemoperitoneum equal to or above the median volume was assessed by calculating $\mathrm{Se}, \mathrm{Sp}$, positive and negative LR on the basis of the patients in our sample population.

Analyses were carried out using the version 5.0 Statview statistics software package (SAS Corporation).

\section{Results}

During the study period 119 patients were operated upon $\mathrm{EP}$, of whom $30(25.2 \%)$ were excluded, as no adequate US image were available $(\mathrm{N}=15)$ or when the haemoperitoneum had not been measured intraoperatively $(\mathrm{N}=$ 15). This left 89 patients to constitute the study population. Baseline characteristics of the population are shown in Table 1.

The median volume of the haemoperitoneum measured at the time of surgery was $300 \mathrm{ml}$. Forty eight $(53.9 \%)$ patients presented haemoperitoneum $\geq 300 \mathrm{ml}$ and 41 patients $(46.1 \%)$ presented no haemoperitoneum or < $300 \mathrm{ml}$ (Table 1 ). Thirty eight patients had tubal rupture $(40.4 \%)$. The proportion of ruptured tubes was markedly higher among patients with a haemoperitoneum $\geq 300 \mathrm{ml}$ (60.4 versus $17.1 \%$; $p<0.0001$ ).

Table I: Characteristics of the study population $(\mathrm{N}=89)$

\begin{tabular}{lccc}
\hline variables & $\mathrm{n}$ & Mean \pm I SD & $\begin{array}{c}\text { Frequency } \\
(\%)\end{array}$ \\
\hline $\begin{array}{l}\text { Age (years) } \\
\text { Gravidity }\end{array}$ & & $30.2 \pm 5.0$ & \\
Gestational age (days) & & $32.9 \pm 1.6$ & \\
Laparoscopy & & & \\
$\quad$ From outset & 76 & & 85.4 \\
$\quad$ Methotrexate failure & 11 & & 12.4 \\
Laparotomy & 2 & & 2.2 \\
Tubal rupture & 36 & & 40.4 \\
Haemoperitoneum (mL) & & \\
$\quad<60$ & 21 & & 23.6 \\
$\quad$ [60-300] & 20 & & 22.5 \\
$\quad$ [300-900] & 37 & & 41.6 \\
$\quad 900$ & 11 & \\
\hline
\end{tabular}

$\mathrm{SD}=$ standard deviation
The crude associations between the studied variables and the existence of massive haemoperitoneum are summarised in Table 2. There was a linear trend between the volume of intraperitoneal fluid at transvaginal sonogram of the uterus and the probability of haemoperitoneum $\geq 300$ $\mathrm{ml}$ at surgery: indeed, $83.3 \%$ of patients with fluid above the uterine fundus, 70.6 with fluid reaching the uterine body and $24.3 \%$ with fluid under the uterine isthmus or absent had haemoperitoneum $\geq 300 \mathrm{ml}$ respectively (Chisquare for linear trend $=20.9$ with 1 degree of freedom; $p$ $<0.0001)$.

The diagnostic values of the variables associated with haemoperitoneum $\geq 300 \mathrm{ml}$ in the univariate analysis are shown in Table 3 . Three variables had a high sensitivity with sufficiently low negative LR: any pelvic pain, moderate to severe pelvic pain, and the presence of any amount of fluid in the pouch of Douglas (Table 3). Four variables a had high specificity and sufficiently high positive LR: a serum haemoglobin concentration $<10 \mathrm{~g} / \mathrm{dl}$, a systolic blood pressure $<100 \mathrm{~mm} \mathrm{Hg}$, fluid above the uterine fundus, and fluid around the ovary (Table 3). As the latter two variables were not inter-connected (Chi-square with 1 degree of freedom $=1.1 ; \mathrm{p}=$ not significant) and each represented a small number of patients, they were combined into a single variable: fluid above the uterine fundus $\mathrm{OR}$ fluid around the ovary.

These variables were all introduced into a multiple regression analysis model. After using the selection procedure, three variables independently predicted the finding of a haemoperitoneum $\geq 300 \mathrm{ml}$ at surgery: moderate to severe pelvic pain, fluid above the uterine fundus OR fluid around the ovary, and a serum haemoglobin concentra-
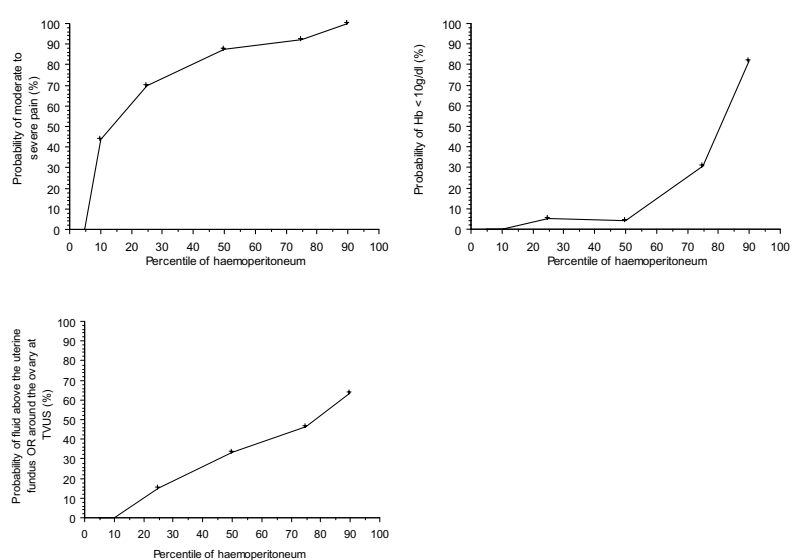

Figure I

Relationship between the amount of haemoperitoneum (expressed in percentile) and the three variables used in the model. 
Table 2: Characteristics and ultrasound findings according to the haemoperitoneum volume at surgery

\begin{tabular}{|c|c|c|c|}
\hline Variables & $\begin{array}{c}\text { Haemoperitoneum }<300 \mathrm{ml} \mathrm{N} \\
=41\end{array}$ & $\begin{array}{l}\text { Haemoperitoneum } \geq 300 \mathrm{ml} \\
\mathrm{N}=48\end{array}$ & $P$ value \\
\hline & Mean \pm I SD & Mean \pm I SD & \\
\hline Age (year) & $30.8 \pm 5.5$ & $29.7 \pm 4.7$ & $0.301 *$ \\
\hline Number of previous pregnancies & $3.0 \pm 1.8$ & $2.9 \pm 1.6$ & $0.718^{*}$ \\
\hline Parity & $1.2 \pm 1.2$ & $1.0 \pm 0.9$ & $0.400 *$ \\
\hline \multirow[t]{2}{*}{ Gestional age (day) } & $34.7 \pm 15.5$ & $31.3 \pm 16.9$ & $0.336 *$ \\
\hline & No $(\%)$ & No (\%) & \\
\hline Vaginal bleeding & $33(80.4)$ & $30(62.5)$ & $0.063 *$ \\
\hline \multicolumn{4}{|l|}{ Spontaneous pelvic pain } \\
\hline Absent & $7(17.1)$ & $0(0)$ & \\
\hline Mild & $13(31.7)$ & $4(8.3)$ & $<0.0011^{\dagger}$ \\
\hline Moderate & $12(29.3)$ & $19(39.6)$ & \\
\hline \multirow[t]{2}{*}{ Severe } & $9(21.9)$ & $25(52.1)$ & \\
\hline & Mean \pm I SD & Mean \pm I SD & \\
\hline Systolic blood pressure $(\mathrm{mmHg})$ & $119.5 \pm 11.7$ & $113.3 \pm 15.3$ & $0.038^{*}$ \\
\hline Diastolic blood pressure $(\mathrm{mmHg})$ & $72.4 \pm 8.9$ & $66.7 \pm 10.0$ & $0.006 *$ \\
\hline Heart rate (pulse/mn) & $83.8 \pm 13.8$ & $85.5 \pm 12.3$ & $0.530 *$ \\
\hline Serum hCG concentration (UI/L) & $7412 \pm 11667$ & $3828 \pm 6465$ & $0.068^{*}$ \\
\hline Serum haemoglobin concentration $(g / d l)$ & $12.0 \pm 1.2$ & $10.5 \pm 1.9$ & $<0.00 I^{*}$ \\
\hline Volume of intraperitoneal fluid at TVUS & No (\%) & No $(\%)$ & \\
\hline Absent & II (26.8) & $4(8.3 \%)$ & \\
\hline$\leq$ Uterine isthmus & $17(41.5)$ & $5(10.4 \%)$ & $<0.001 \dagger$ \\
\hline Uterine body & $10(24.4)$ & $24(50.0 \%)$ & \\
\hline$>$ Uterine fundus & $3(7.3)$ & $15(31.3 \%)$ & \\
\hline Clots present at TVUS & $12(29.3)$ & $35(72.9)$ & $<0.001 \dagger$ \\
\hline Fluid around the ovary at TVUS & I (2.4) & $8(16.7)$ & $0.027 \dagger$ \\
\hline \multirow[t]{2}{*}{ Fluid in the vesico-uterine pouch at TVUS } & $5(12.8)$ & $5(10.6)$ & $0.753 \dagger$ \\
\hline & Mean \pm I SD & Mean \pm I SD & \\
\hline Height of fluid in Pouch of Douglas $(\mathrm{mm} \pm \mathrm{I} S \mathrm{SD}) \ddagger$ & $20.8 \pm 10.2$ & $26.5 \pm 12.0$ & $0.039 *$ \\
\hline Width of fluid in Pouch of Douglas ( $\mathrm{mm} \pm \mathrm{I}$ SD) $\ddagger$ & $29.3 \pm 25.9$ & $50.8 \pm 24.3$ & $<0.00 I^{*}$ \\
\hline
\end{tabular}

$\mathrm{SD}=$ standard deviation. TVUS = transvaginal ultrasound examination

* Student's t-test.

† Chi square for heterogeneity.

f for one woman the measurement was not available.

tion $<10 \mathrm{~g} / \mathrm{dL}$ (Table 4). Although Serum hCG $<5000$ had no interesting diagnostic value (Table 3 ) it was still included in the multiple regression analysis model in order to avoid any confusion bias. Indeed the Serum hCG concentration was used to select patients who may undergo medical therapy.

Assessment for the best combination of these three variables is given in Table 5 . Given a $53.9 \%$ prevalence of haemoperitoneum $\geq 300 \mathrm{ml}$ in the overall population, a patient with none of the three criteria would have a probability of $5.3 \%$ for a haemoperitoneum $\geq 300 \mathrm{ml}$. Inversely when two or more criteria are present, the probability for a haemoperitoneum $\geq 300 \mathrm{ml}$ is in between 92.6 and $100.0 \%$.

Relations between the quantification of haemoperitoneum, expressed in percentile, and the three variables of the model are plotted on figure 1 . There is an increasing relationship between the amount of the haemoperito- neum and each of the three variable used in the prediction model.

\section{Discussion}

We have developed a clinical prediction model for the diagnosis of significant haemoperitoneum in patients with EP. This model was based on three simple and reproducible criteria: The presence of moderate to severe spontaneous pelvic pain, the presence of intraperitoneal fluid above the uterine fundus or around the ovary at transvaginal US, and the existence of a serum haemoglobin concentration $<10 \mathrm{~g} / \mathrm{dL}$. We found that this model may reliably rule out or confirm preoperatively, the existence of a significant haemoperitoneum at surgery.

One of the biggest limitations of our study is that it was retrospective. As an example, assessment of the severity of the pain was based on the attending phycisian's interpretation of the patient's pain and no strict criteria such as self-evaluation by a visual analog scale was used [27]. This 
Table 3: Diagnostic value of the variables found to be predictive of haemoperitoneum $\geq \mathbf{3 0 0} \mathbf{~ m l}$ at univariate analysis at their best cutoff point

\begin{tabular}{|c|c|c|c|c|c|c|}
\hline Variable & Patients with the characteristic & $\mathrm{Se}(\%)$ & $\mathrm{Sp}(\%)$ & $\mathrm{LR}+$ & LR - & $\mathrm{P}$-value* \\
\hline Vaginal bleeding absent & 26 & 37.5 & 80.5 & 1.92 & 0.78 & 0.063 \\
\hline Any pelvic pain & 82 & 100.0 & 17.1 & 1.21 & 0.00 & 0.003 \\
\hline Moderate to severe pelvic pain & 65 & 91.5 & 48.8 & 1.8 & 0.2 & $<0.001$ \\
\hline Systolic blood pressure $<100 \mathrm{~mm} \mathrm{Hg}$ & 12 & 20.8 & 95.1 & 4.27 & 0.83 & 0.0215 \\
\hline $\mathrm{Hb}<10 \mathrm{~g} / \mathrm{dl}$ & 15 & 29.2 & 97.6 & 11.9 & 0.73 & 0.001 \\
\hline Serum hCG $<5000 \mathrm{IU} / \mathrm{L}$ & 66 & 83,3 & 36,6 & $|, 3|$ & 0,46 & 0,032 \\
\hline Any fluid in the pouch of Douglas at TVUS & 74 & 91.7 & 26.8 & 1.25 & 0.31 & 0.020 \\
\hline Fluid > uterine isthmus at TVUS & 52 & 81.3 & 68.3 & 2.56 & 0.27 & $<0.001$ \\
\hline Fluid $>$ uterine fundus at TVUS & 18 & 31.1 & 92.7 & 4.27 & 0.74 & 0.005 \\
\hline Fluid arround the ovary at TVUS & 9 & 16.7 & 97.6 & 6.83 & 0.85 & 0.027 \\
\hline Fluid $>$ uterine fundus OR fluid arround the ovary at TVUS & 24 & 43.8 & 92.7 & 5.98 & 0.61 & $<0.001$ \\
\hline Fluid height $\geq 1 \mathrm{I} \mathrm{mm}$ at TVUS & 65 & 85.1 & 39.0 & 1.40 & 0.38 & 0.010 \\
\hline Fluid Width $\geq 20 \mathrm{~mm}$ at TVUS & 66 & 89.4 & 41.5 & 1.53 & 0.26 & 0.001 \\
\hline Clots present at TVUS & 47 & 72.9 & 70.7 & 2.5 & 0.4 & $<0.001$ \\
\hline
\end{tabular}

$\mathrm{Hb}=$ Serum haemoglobin concentration. $\mathrm{LR}+=$ positive likelihood ratio. $\mathrm{LR}-=$ negative likelihood ratio. Se $=$ sensitivity. Sp $=\mathrm{specificity.} \mathrm{TVUS=}$ transvaginal ultrasound examination.

* Chi square for heterogeneity.

may lead to a substantial interobserver difference in graded pain. There is nonetheless a fair agreement between physicians and patients' estimates of pain [28]. The quality of US data used in this study relies in the fact the fact that the information was not gathered from a written report in the patient's notes, but that they were obtained by re-interpreting standardised sonograms blind to surgical findings. Patients for whom we did not retrieve standardised transvaginal sonograms were excluded from the study. Nevertheless, prospective validation studies of samples from different centres are important to evaluate the actual predictive ability of a diagnostic model [29].

Although our criteria appeared to be reliable to exclude the presence of massive haemoperitoneum, there may be a tubal rupture in the absence of any significant haemo-

Table 4: Independent predictors of haemoperitoneum $\geq 300 \mathrm{ml}$ using multiple regression analysis

\begin{tabular}{lcc}
\hline Variables & Adj. OR* & $95 \% \mathrm{Cl}$ \\
\hline $\mathrm{Hb}<10 \mathrm{~g} / \mathrm{dL}$ & & \\
$\quad$ No & $\mathrm{I}$ & Ref. \\
$\quad$ Yes & 20.0 & $1.9-214.1$ \\
$\begin{array}{l}\text { Spontaneous pelvic pain } \\
\quad \text { None to mild }\end{array}$ & $\mathrm{I}$ & Ref. \\
$\quad$ Moderate to severe & $\mathrm{II} .5$ & $2.3-57.2$ \\
Fluid $>$ uterine fundus OR fluid around the & & \\
ovary at TVUS & & \\
$\quad$ No & I & Ref. \\
Yes & I2.9 & $2.5-65.5$
\end{tabular}

$\mathrm{Hb}=$ Serum haemoglobin concentration. Adj. OR = Adjusted Odds Ratio. $\mathrm{Cl}=$ confidence interval. Ref. $=$ reference class for the variable.

* The variable Serum hCG $<5000$ was introduced in the model in order to avoid confusion bias peritoneum in up to $27 \%$ of the cases $[17,30]$. However, this type of tubal rupture is probably unlikely to cause active bleeding at the time of diagnosis, but secondary resumption of bleeding could explain some of the failures observed after treatment by methotrexate, including cases with no intraperitoneal effusion $[11,19]$. This was the case for two patients in our study who had a tubal rupture with no active bleeding and a haemoperitoneum of $30 \mathrm{ml}$ and $120 \mathrm{ml}$ respectively. Anyway, our model, which was specifically designed to predict the existence of massive haemoperitoneum, is in agreement with a previously developed model for prediction of tubal rupture or active bleeding in EP [15]. Indeed, in this model, the three most important criteria were the existence of an intraperitoneal effusion at transvaginal US, any spontaneous abdominal pain and $\mathrm{Hb} \leq 9.7 \mathrm{~g} / \mathrm{dl}$. The match between this model and ours confirms the fact that pre operative diagnosis of tubal rupture is mostly based on the presence of haemoperitoneum.

Appropriate quantification of intraperitoneal fluid at US is important because fluid in the Pouch of Douglas may be present in up to $80 \%$ of EP whether ruptured or not $[17,31]$. A semi-quantitative estimate of haemoperitoeum volume, using transvaginal US examination of the uterus in a midsagittal plane, which we have used (adapted from [18]) showed an excellent correlation with the volume of haemoperitoneum measured during surgery. We elected to use this classification because it is based on a standard ultrasound plane that is easy to obtain, and on criteria that seem reproducible. Two other ultrasound classifications have been proposed to assess the quantity of haemoperitoneum. One author [20] differentiates three classes of effusion: $\leq 10 \mathrm{ml}, 10 \mathrm{ml}$ to $100 \mathrm{ml}$ and $>100 \mathrm{ml}$, with- 
Table 5: Classification and diagnostic value of the different combinations of the independent criterias predicting haemoperitoneum $\geq$ $300 \mathrm{ml}$

\begin{tabular}{|c|c|c|c|c|c|c|}
\hline & $\begin{array}{l}\text { Patients with the } \\
\text { characteristic }\end{array}$ & $\begin{array}{c}\text { probability of } \\
\text { haemoperitoneum } \geq 300 \mathrm{ml}\end{array}$ & Se (\%) & Sp (\%) & $\mathrm{LR}+$ & LR - \\
\hline Overall population & 89 & 0.54 & & & & \\
\hline \multicolumn{7}{|l|}{ Low risk of massive haemoperitoneum } \\
\hline $\begin{array}{l}\text { Absent to mild pelvic pain AND } \mathrm{Hb} \geq 10 \mathrm{~g} / \mathrm{dL} \\
\text { AND no fluid above the uterus or around the } \\
\text { ovary at TVUS }\end{array}$ & 19 & 0.05 & $97.9 *$ & $43.9 *$ & $1.75^{*}$ & $0.05^{*}$ \\
\hline \multicolumn{7}{|l|}{ High risk of massive haemoperitoneum } \\
\hline $\begin{array}{l}\text { Moderate to severe pelvic pain AND } \mathrm{Hb}<10 \\
\mathrm{~g} / \mathrm{dL}\end{array}$ & 14 & 0.93 & 27.1 & 97.6 & 11.10 & 0.75 \\
\hline $\begin{array}{l}\text { Moderate to severe pelvic pain AND fluid } \\
\text { above the uterus or around the ovary at TVUS }\end{array}$ & 20 & 0.95 & 39.6 & 97.6 & 16.23 & 0.62 \\
\hline Two criteria present $\dagger$ & 27 & 0.93 & 52.1 & 95.1 & 10.68 & 0.50 \\
\hline All of the 3 criteria present $\dagger$ & 7 & 1.00 & 14.6 & 100.0 & $\infty$ & 0.85 \\
\hline
\end{tabular}

$\mathrm{Hb}=$ serum haemoglobin concentration. TVUS = transvaginal ultrasound examination.

* Calculated for the absence of the disease. $†$ All women with fluid above the uterus or around the ovary at transvaginal ultrasound examination and $\mathrm{Hb}<10 \mathrm{~g} / \mathrm{dL}$ had moderate to severe pain.

out however setting any precise ultrasound criteria. Others $[21,32]$ subjectively quantified the amount of intraperitoneal fluid as small, moderate or large. Although these last two classifications are often used to predict the haemoperitoneum volume prior to medical treatment of EP, they have never been subjected to a correlation with the volume found at surgery.

Our clinical model for prediction of massive haemoperitoneum may be useful for the medical management of EP. When none of the three criteria is present, medical treatment and follow-up as an outpatient is, to our opinion, possible. Accordingly, the model fits well with wellknown countraindications for methotrexate [19] Sowter, 2001; Rozenberg, 2003]. However these contraindications were so far solely based on clinical opinion. Because the absence of all three criteria in the population study was rather uncommon, one may question the usefulness of the model in clinical practice. Our centre has been supporting medical treatment for EP for the last 10 years $[10,33]$ and most patients with obvious criterias for medical treatment were unlikely to be selected in the present study. When used in a more general population of women with $\mathrm{EP}$, the negative predictive value of our model for the diagnosis of significant haemoperitoneum is therefore likely to increase.

Finally, our clinical prediction model should be further tested and may prove useful to monitor patient with methotrexate treatment. Indeed, spontaneous pelvic pain occurs frequently during this treatment. Although in most cases the outcome is spontaneously favourable, this situation does raise concerns and often leads to unnecessary laparoscopy $[30,34,35]$. Our model may help in the man- agement of these patients: as increasing haemoperitoneum at transvaginal US or a drop in haemoglobin concentration would suggest that laparoscopy should be performed.

\section{Conclusion}

Three criteria may predict massive haemoperitoneum in EP: moderate to severe spontaneous pelvic pain, fluid above the uterine fundus or around the ovary at ultrasound, and low serum haemoglobin concentration. The proposed model accurately predicted significant haemoperitoneum in patients diagnosed to have EP. It could be used to select patients who should not undergo medical treatment. The usefulness of the proposed model should be tested prospectively as part of routine triage of patients with suspected EP in the emergency department.

\section{Abbreviations}

EP: Ectopic pregnancy

US: ultrasound

hCG: human chorionic gonadotropin

\section{Competing interests}

The author(s) declare that they have no competing interests.

\section{Authors' contributions}

All authors read and approved the final manuscript.

AF conceived of the study, and participated in its design and coordination and drafted the manuscript. 
AM participated in the design of the study, carried out the review of sonograms, abstracted the data and performed the statistical analysis.

LS helped to perform the statistical analysis, and helped to draft the manuscript.

J-PB participated in the design of the study and helped to carried out the review of sonograms.

YV participated in the design and coordination of the study and helped to draft the manuscript.

\section{References}

I. Ankum WM, Van der Veen F, Hamerlynck JV, Lammes FB: Laparoscopy: a dispensable tool in the diagnosis of ectopic pregnancy? Hum Reprod 1993, 8(8): I30I-I306.

2. Kaplan BC, Dart RG, Moskos M, Kuligowska E, Chun B, Adel Hamid $M$, Northern K, Schmidt J, Kharwadkar A: Ectopic pregnancy: prospective study with improved diagnostic accuracy. Ann Emerg Med 1996, 28(I):10-17.

3. Mol BW, Hajenius PJ, Engelsbel S, Ankum WM, Van der Veen F, Hemrika DJ, Bossuyt PM: Serum human chorionic gonadotropin measurement in the diagnosis of ectopic pregnancy when transvaginal sonography is inconclusive. Fertil Steril 1998, 70(5):972-98I.

4. Stovall T, Ling F: Ectopic pregnancy. Diagnostic and therapeutic algorithms minimizing surgical intervention. J Reprod Med 1993, 38:807-812.

5. Mol BW, van der Veen F, Bossuyt PM: Symptom-free women at increased risk of ectopic pregnancy: should we screen? Acta Obstet Gynecol Scand 2002, 8 I (7):66I-672.

6. Saxon D, Falcone T, Mascha EJ, Marino T, Yao M, Tulandi T: A study of ruptured tubal ectopic pregnancy. Obstet Gynecol 1997, 90(I):46-49.

7. Job-Spira N, Fernandez H, Bouyer J, Pouly JL, Germain E, Coste J: Ruptured tubal ectopic pregnancy: risk factors and reproductive outcome: results of a population-based study in France. Am J Obstet Gynecol 1999, I 80(4):938-944.

8. Saraj AJ, Wilcox JG, Najmabadi S, Stein SM, Johnson MB, Paulson RJ: Resolution of hormonal markers of ectopic gestation: a randomized trial comparing single-dose intramuscular methotrexate with salpingostomy. Obstet Gynecol 1998, 92(6):989-994.

9. Hajenius PJ, Engelsbel S, Mol BW, Van der Veen F, Ankum WM, Bossuyt PM, Hemrika DJ, Lammes FB: Randomised trial of systemic methotrexate versus laparoscopic salpingostomy in tubal pregnancy. Lancet 1997, 350(9080):774-779.

10. Rozenberg P, Chevret S, Camus E, de Tayrac R, Garbin O, de Poncheville L, Coiffic J, Lucot JP, Le Goueff F, Tardif D, Allouche C, Fernandez $\mathrm{H}$ : Medical treatment of ectopic pregnancies : a randomized clinical trial comparing methotrexate-mifepristone and methotrexate-placebo. Hum Reprod 2003, I 8(9): 1802-1808.

II. Nazac A, Gervaise A, Bouyer J, de Tayrac R, Capella-Allouc S, Fernandez $\mathrm{H}$ : Predictors of success in methotrexate treatment of women with unruptured tubal pregnancies. Ultrasound Obstet Gynecol 2003, 2 I (2): I8I-185.

12. Sowter MC, Farquhar CM, Petrie KJ, Gudex G: A randomised trial comparing single dose systemic methotrexate and laparoscopic surgery for the treatment of unruptured tubal pregnancy. Bjog 200I, 108(2): 192-203.

13. Fauconnier A, Mabrouk A, Heitz D, Ville Y: Grossesse extrautérine: intérêt et valeur de l'examen clinique dans la stratégie de prise en charge [Ectopic pregnancy: interest and value of clinical examination in management policy]. J Gynecol Obstet Biol Reprod (Paris) 2003, 32(7 Suppl):SI 8-27.

14. Hirata AJ, Soper DE, Bump RC, Hurt WG: Ectopic pregnancy in an urban teaching hospital: can tubal rupture be predicted? South Med I I 991, 84(I2): I467-| 469 .

15. Mol BW, Hajenius PJ, Engelsbel S, Ankum WM, van der Veen F, Hemrika DJ, Bossuyt PM: Can noninvasive diagnostic tools predict tubal rupture or active bleeding in patients with tubal pregnancy? Fertil Steril 1999, 7 I(I):167-173.

16. Stovall TG, Kellerman AL, Ling FW, Buster JE: Emergency department diagnosis of ectopic pregnancy. Ann Emerg Med 1990, 19(10): 1098-1103.

17. Frates MC, Brown DL, Doubilet PM, Hornstein MD: Tubal rupture in patients with ectopic pregnancy: diagnosis with transvaginal US. Radiology 1994, 19 I(3):769-772.

18. Dart R, McLean SA, Dart L: Isolated fluid in the cul-de-sac: how well does it predict ectopic pregnancy? Am J Emerg Med 2002, 20(I): $1-4$.

19. Lipscomb GH, McCord ML, Stovall TG, Huff G, Portera SG, Ling FW: Predictors of success of methotrexate treatment in women with tubal ectopic pregnancies. N Engl J Med 1999, 34 I(26): I 974-1978.

20. Fernandez $H$, Lelaidier $C$, Thouvenez V, Frydman R: The use of a pretherapeutic, predictive score to determine inclusion criteria for the non-surgical treatment of ectopic pregnancy. Hum Reprod 1991, 6(7):995-998.

21. Nyberg DA, Hughes MP, Mack LA, Wang KY: Extrauterine findings of ectopic pregnancy of transvaginal US: importance of echogenic fluid. Radiology 1991, 178(3):823-826.

22. Benhamou D: [Evaluation of postoperative pain]. Ann Fr Anesth Reanim 1998, I 7(6):555-572.

23. Sickler GK, Chen PC, Dubinsky TJ, Maklad N: Free echogenic pelvic fluid: correlation with hemoperitoneum. J Ultrasound Med 1998, 17(7):431-435.

24. Chen PC, Sickler GK, Dubinsky TJ, Maklad N, Jacobi RL, Weaver JE: Sonographic detection of echogenic fluid and correlation with culdocentesis in the evaluation of ectopic pregnancy. AJR Am J Roentgenol 1998, I70(5): 1299-1302.

25. Jeffrey RB, Laing FC: Echogenic clot: a useful sign of pelvic hemoperitoneum. Radiology 1982, I45(1):|39-|4|

26. Buckley RG, King KJ, Disney JD, Ambroz PK, Gorman JD, Klausen JH: Derivation of a clinical prediction model for the emergency department diagnosis of ectopic pregnancy. Acad Emerg Med 1998 ,

5(10):951-960.

27. Gallagher EJ, Bijur PE, Latimer C, Silver W: Reliability and validity of a visual analog scale for acute abdominal pain in the ED. Am J Emerg Med 2002, 20(4):287-290.

28. Hodgkins M, Albert D, Daltroy L: Comparing patients' and their physicians' assessments of pain. Pain 1985, 23(3):273-277.

29. Coste J, Bouyer J, Job-Spira N: Construction of composite scales for risk assessment in epidemiology: an application to ectopic pregnancy. Am J Epidemiol 1997, 145:278-289.

30. Heard K, Kendall J, Abbott J: Rupture of ectopic pregnancy after medical therapy with methotrexate: a case series. J Emerg Med 1998, I6(6):857-860.

31. DiMarchi JM, Kosaka TS, Hale RW: What is the significance of the human chorionic gonadotropin value in ectopic pregnancy? Obstet Gynecol 1989, 74:85I-855.

32. Atri M, Leduc C, Gillett P, Bret PM, Reinhold C, Kintzen G, Aldis AE, Thibodeau M: Role of endovaginal sonography in the diagnosis and management of ectopic pregnancy. Radiographics 1996, 16(4):755-774.

33. Perdu M, Camus E, Rozenberg P, Goffinet F, Chastang C, Philippe H], Nisand I: Treating ectopic pregnancy with the combination of mifepristone and methotrexate: a phase II nonrandomized study. Am J Obstet Gynecol 1998, I79(3 Pt I):640-643.

34. Stovall TG, Ling FW: Single-dose methotrexate: an expanded clinical trial. Am J Obstet Gynecol 1993, I68(6 Pt I): 1759-1762.

35. Lipscomb GH, Puckett KJ, Bran D, Ling FW: Management of separation pain after single-dose methotrexate therapy for ectopic pregnancy. Obstet Gynecol 1999, 93(4):590-593. 